\title{
REDESAIN STASIUN BLOK-M
}

\author{
Andy Putra ${ }^{1)}$, Tony Winata ${ }^{2)}$ \\ 1)Program Studi S1 Arsitektur, Fakultas Teknik, Universitas Tarumanagara, andyputra96@hotmail.com \\ 2)Program Studi S1 Arsitektur, Fakultas Teknik, Universitas Tarumanagara, tonywinata@ft.untar.ac.id
}

\begin{abstract}
Abstrak
Kalangan milenial merupakan salah satu kalangan yang mendorong perekonomian Indonesia dengan kreatifitasnya, untuk menuju ekonomi yang berbasis kepada ekonomi kreatif. Kota Jakarta merupakan kota yang didominasi oleh banyaknya tempat untuk mengembangkan talentanya, tempat untuk menunjukkan kreatifitas serta tempat untuk menyebarkan atau mempengaruhi sekitarnya berupa produk yang bersifat inovatif. Oleh karena itu, banyaknya penduduk komuter atau luar kota datang ke Jakarta untuk mempelajari serta mengembangkan kegemarannya dengan cara yang berbeda-beda, ada yang bekerja, magang, belajar, dan sebagainya untuk mengembangkan potensinya. Pembaharuan stasiun bus Blok-M memberikan ruang untuk membantu komuter untuk dapat berdatangan ke Jakarta serta menyediakan wadah didalamnya dalam hal-hal baru yang memiliki penerapan dalam hal pengembangan kreatifitas serta perekonomian kreatif yang bersifat interaktif dan kolaboratif dengan memadukan konsep berbagi (bersifat visual maupun komunikatif). Adapun penambahan fungsi baru untuk memenuhi kualitas stasiun bus serta pemenuhan yang melingkupi sekitarnya seperti adanya penambahan ruang tunggu bus, ruang baca, dan area kreatifitas serta konsep fasad bangunan yang memperlihatkan pembagian zona perpindahan dengan kreatiftitas yang diterapkan dengan adanya alur likukan-likukan mencerminkan kreatifitasan tanpa batas.
\end{abstract}

Kata Kunci: ekonomi kreatif; komuter; kreatif; milenial stasiun

\begin{abstract}
The millennial generation is one of the generations that supports in the advancement of Indonesian economy through the utilization of their creativity, in order to achieve the targeted proportion of creative economy as a whole. Jakarta is a city that is dominated by many spaces that support the development of individual talents, showcase their own creativity as well as to influence the general public through innovative products. To achieve it, many commuters enter Jakarta everyday to open themselves up to possibilities of selfimprovement and self-development in many different ways: working, having internship, studying and many more to develop their individual potency. The redesign of Blok $M$ bus station provides a new contemporary space for commuters that travel to Jakarta as well as a series of spaces that helps in driving the millennials toward creative possibilities through interactive and collaborative methods (both visually and communicatively). The addition of new functions to meet the bus station quality and fulfillment that surrounds it such as the addition of bus waiting rooms, reading rooms, and areas of creativity and building façade concept showcases different zoning for creativity that is applied, whilst the curvilinear form reflects endless creativity.
\end{abstract}

Keywords: comuter; creative; economy creative; millennials; station

\section{PENDAHULUAN}

DKI Jakarta sebagai ibukota Indonesia adalah pusat bisnis dan pusat pemerintahan dengan jumlah penduduk tahun 2016 mencapai 10.277,628 juta orang dan kepadatan penduduk 15.517 orang per km2, dikelilingi kawasan pemukiman Bogor, Depok, Tangerang dan Bekasi (Bodetabek) yang semakin berkembang. Dari hasil survei komuter Jabodetabek tahun 2014 menunjukkan, bahwa jumlah komuter Jabodetabek sebanyak 3.566 .178 orang, terdiri dari 2.429.751 orang melakukan kegiatan bekerja dan sekolah/kursus di DKI Jakarta, 1.067.762 
orang di Bodetabek, dan 68.665 orang di luar Jabodetabek. Sementara komuter Bodetabek yang melakukan kegiatan di DKI Jakarta sebanyak 1.382.296 orang.

Seiring perkembangan jaman, pertumbuhan generasi milenial yang semakin banyak. Kondisi ini menunjukkan bahwa harus adanya moda untuk menampung para milenial dalam bentuk apapun terutama dalam bidang transportasi yang dikarenakan sifat dari pertumbuhan kota yang berbeda-beda terutama di kota besar seperti Jakarta yang selalu diakses oleh penududuk di luar Jakarta (komuter) untuk melakukan perkembangan ilmu ( belajar, bekerja, dsb ). Maka dari itu, menunjukkan transportasi umum merupakan kebutuhan yang mendesak karena tumbuh kembangnya sektor transportasi yang baik akan memberikan perkembangan yang cukup besar bagi perkembangan di sektor lain seperti perdagangan, perindustrian, keuangan, dan jasa-jasa (sumber: Jakarta.bps.go.id). Milenial juga memiliki pengaruh dalam sektor industri terutama industri kreatif.

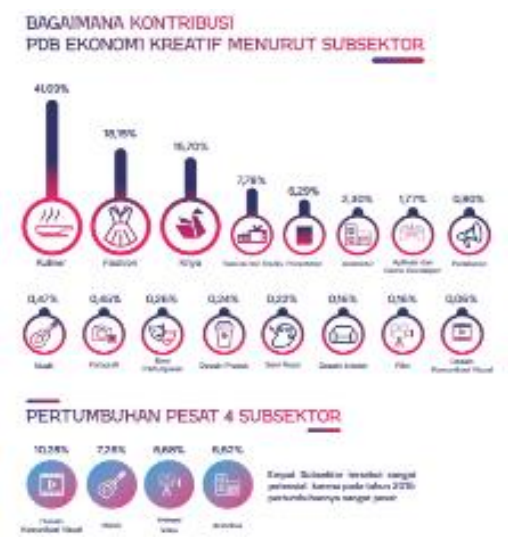

Gambar 1. Kontribusi PDB ekonomi kreatif tahun 2015

Sumber: Data Statistik Ekonomi Kreatif Indonesia

Dari Gambar 1, didapati bahwa peran ekonomi kreatif bagi perkembangan ekonomi di Indonesia sangat besar dan terus mengalami kenaikan setiap tahunnya dan Indonesia sudah berada di peringkat ketiga dengan kontribusi ekonomi kreatif tertinggi di dunia. Untuk membantu milenial pada pengembangan ekonomi kreatif diperlukan creative space yang membantu milenial dan mengumpulkan ide baik individu maupun berkolaborasi, maka salah satu lokasi yang paling efektif ialah "public space" pada fasilitas transportasi umum seperti stasiun transit yang bersifat antar kota serta lokasi yang memiliki acara dan trend yang selalu berkembang di daerah tersebut yaitu daerah Jakarta Selatan-Pusat maka dari itu, memilih pusat perpindahan moda terbanyak di Jakarta Selatan ialah Terminal Bus Blok-M.

Tujuan utama pembuatan proyek ini yaitu mengajak millennials untuk dapat memakai kendaraan umum yang dibekali area transit yang bersifat bekerja dan leisure agar dapat beradaptasi dengan perilaku millennials sehingga dapat mengurangi kepadatan kendaraan di pusat kota Jakarta yang cenderung akibat kepadatan mobilitas yang disebabkan oleh pemakaian kendaraan pribadi dari kota-kota komuter dan fasilitas angkutan umum yang masih kurang baik serta membuat masyarakat terutama para millennials yang saat ini memegang pasar perekonomian creative yang datang dari komuter ke Jakarta untuk mengembangkan seni kreatifnya dan bekerja dalam bidang kreatif dengan dominasi tren dan tempat pembelajaran yang berada di daerah Jakarta Selatan-Pusat ini memungkinkan untuk melakukan program yang dapat berhubungan antara bidang seni dan transportasi umum agar dapat meningkatkan minat masyarakat terutama millennials untuk menggunakan transportasi umum dengan mengkombinasikan stasiun transit yang berada di Blok $M$ dengan program seni. Adapun misi yang akan dilakukan dalam proyek ini adalah untuk membuat program baru pada stasiun transit yang menjadikannya sebagai titik perekonomian dan rekreasi, creative-space, art-space untuk membuat milenial datang untuk mengenal lebih tentang seni yang sedang trend. 


\section{KAJIAN LITERATUR}

Kajian literatur memberikan arahan serta teori-teori yang ada untuk menjadi instrumen terhadap tema soal yang bertemakan milenial dan perilaku serta tentang proyek yang telah dipilih.

\section{Pengertian Generasi}

Untuk memahami dan menguasai tema proyek tentang Millennials, Type and Behaviour. Perlu dilakukan pemahaman terlebih dahulu tentang generasi, serta tipe dan perilaku tiap generasi. Generasi secara sederhana dapat diartikan sebagai suatu masa di mana kelompok manusia pada masa tersebut mempunyai keunikan yang dapat memberi ciri pada dirinya dan pada perubahan sejarah atau zaman.

Menurut Notosusanto, pengertian generasi itu sendiri sebenarnya lebih berlaku untuk kelompok inti yang menjadi panutan masyarakat zamannya, yang dalam suatu situasi sosial dianggap sebagai pimpinan atau paling tidak penggaris pola zamannya (pattern setter). $\mathrm{Di}$ Indonesia, dianggap telah memiliki 4 generasi yaitu generasi Baby Boomers, $\mathrm{X}, \mathrm{Y}$ dan $\mathrm{Z}$.

Generasi $Y$ dikenal juga sebagai generasi milenial, yaitu generasi setalah generasi Baby Boomers, X (1965-1980). Generasi Y menurut Fourhooks, generasi Y merupakan generasi yang lahir pada tahun 1981-1994 yang pada zaman ini merupakan populasi terbanyak didunia dan merupakan generasi yang akan mendominasi perekonomian di dunia dengan menggunakan kreativitasnya dan teknologi yang semakin maju seperti dapat memadukan kreativitas dan teknologi untuk membuat bisnis dalam bidang startup misalnya facebook, gojek, dll.

\section{Generasi Milenial}

Beberapa perilaku milenial yang umum berdasarkan sumber "fourhooks"

Tabel 1. Perilaku umum milenial

\begin{tabular}{|c|c|}
\hline General & $\begin{array}{l}\text {-Generasi Y menyukai hidup seimbang serta pekerja keras namun lebih } \\
\text { mementingkan "me time". } \\
\text {-Dipengaruhi perkembangan teknologi. }\end{array}$ \\
\hline $\begin{array}{l}\text { Preferred Work } \\
\text { Environment }\end{array}$ & $\begin{array}{l}\text {-Suasana kerja yang bersifat kekeluargaan } \\
\text {-Fleksibilitas } \\
\text {-Selalu memberikan tantangan baru } \\
\text {-Kolaborasi antar rekan kerja yang baik }\end{array}$ \\
\hline Work Liabilities & $\begin{array}{l}\text {-Pekerja keras } \\
\text {-Berekspresi tinggi } \\
\text {-Mematuhi struktur yang jelas dalam bekerja } \\
\text {-Berorientasi pada cara kerja } \\
\text {-Lembur bukan masalah besar } \\
\text {-Tempat kerja adalah rumah kedua }\end{array}$ \\
\hline Core Values & $\begin{array}{l}\text {-Realistis } \\
\text {-Disiplin } \\
\text {-Mementingkan prestasi kerja } \\
\text {-Penuh keinginan } \\
\text {-Memanfaatkan teknologi } \\
\text {-Suka dengan perbedaan } \\
\text {-Memiliki toleransi yang tinggi }\end{array}$ \\
\hline Work Ethic & $\begin{array}{l}\text {-Ambisius, multitasking } \\
\text {-Selalu mencari tantangan } \\
\text {-Suka membangun usaha sendiri } \\
\text {-Giat dan ulet bekerja }\end{array}$ \\
\hline $\begin{array}{l}\text { Feedback \& } \\
\text { Rewards }\end{array}$ & $\begin{array}{l}\text { Milenial akan bertanya serta meminta kritik dan saran. Reward terbaik adalah } \\
\text { perasaan ketika pekerjaannya dinilai berarti. }\end{array}$ \\
\hline
\end{tabular}




\begin{tabular}{ll}
\hline Communication & -Ketika hal yang diperbincangkan sangat serius, lebih baik bicara empat mata \\
& walaupun diawali dengan chat personal \\
& -Meski sopan, namun tidak suka dengan pembicaraan dengan gaya yang serius. \\
& -Suka menyapa terlebih dahulu \\
\hline Work and & Keseimbangan gaya hidup dan pekerjaan menjadi hal yang penting karena \\
Personal Life & milenial cenderung mencari pekerjaan yang dapat menunjang gaya hidupnya. Jika \\
& tidak, milenial cenderung berhenti dari pekerjaannya
\end{tabular}

Sumber: fourhooks

\section{Stasiun Transit}

Definisi stasiun tempat menunggu bagi calon penumpang kendaraan umum bermuatan banyak dan tempat perhentian kendaraan umum bermuatan banyak seperti: bus, kereta api, pesawat, dll. Definisi Transit adalah Transit adalah tempat pemberhentian, pertukaran, pergantian ataupun persinggahan unit untuk sementara waktu yang akan dilanjutkan ke tempat tujuan yang telah ditentukan. (sumber: Highway Capacity Manual, 2000)

\section{Stasiun Bus}

Bermula dari pemberhentian bus (Bus-Stop) yang tergantung dari besaran muatan busnya tersendiri dari yang kecil (single) hingga besar (bus gandeng) atau bus bertingkat yang terletak di samping jalan dan berdekatan dengan lampu lalu-lintas yang diwadahi fasilitas-fasilitas eksisting yang diberikan oleh masyarakat sekitar misalnya tempat berjualan, tempat makan, dan sebagainya di sekitar jalan (street mall) berdasarkan "Highway Capacity Manual, 2000 (TRB,2000). Oleh karena itu, desain bus-stop ini sangat membantu orang-orang dalam hal waktu dan kenyamanan yang disesuaikan dengan timer lampu lalu lintas.

Berdasarkan HCM2000 dan "Geometric Design Guide for Transit Facilities on Highways and Streets, Chapter5 tentang "Off-Line Transit Facilities" (AASHTO, 2010) yang menjelaskan tentang tipe kapasitas bus berdasarkan waktu tinggal bus yaitu:

- Bus loading daerah (tempat berpindah): berada di tepi jalan yang diberikan ruang dimana bus tunggal dapat berhenti untuk menaikan dan menurunkan penumpang.

- Halte Bus: dapat mencakup satu atau lebih bus tergantung pada berapa banyak bus yang menggunakan pemberhentian bus.

- Bus Fasilitas: terdapat di samping jalan raya yang digunakan oleh bus serta terdapat area untuk menunggu berupa shelter.

Dalam HCM2000 model halte bus tergantung pada kapasitas pengguna tiap daerah yang membentuk halte bus misalnya:

- Faktor utama adalah jumlah bus yang dapat diberikan ke publik tergantung pada saat bus diam (pada saat berada di area penjemputan), yang mewakili jumlah rata-rata waktu bus berhenti di trotoar untuk melayani penumpang serta termasuk waktu yang dibutuhkan untuk membuka dan menutup pintu.

- Faktor kedua adalah Time Clearance, yang mewakili rata-rata waktu minimum yang diperlukan untuk satu bus untuk meninggalkan tempat pemberhentian agar bus berikutnya dapat menggunakan waktunya untuk menjemput penumpang dengan tepat waktu dengan tidak menggangun lalu lintas. Hubungan dari dua faktor diatas ini menentukan waktu ratarata bus individu menempati area penjemputan.

- Faktor ketiga adalah tingkat kegagalan didefinisikan sebagai kemungkinan bahwa satu bus akan tiba di area penjemputan sementara bus lain sudah menempati tempat tersebut terlebih dahulu. Kombinasi variabilitas waktu tinggal dan desain tingkat kegagalan menyediakan margin tambahan waktu dalam analisis kapasitas untuk memastikan bahwa kebanyakan bus akan dapat segera menggunakan area penjemputan pada saat kedatangan. (AASHTO, 2010). 


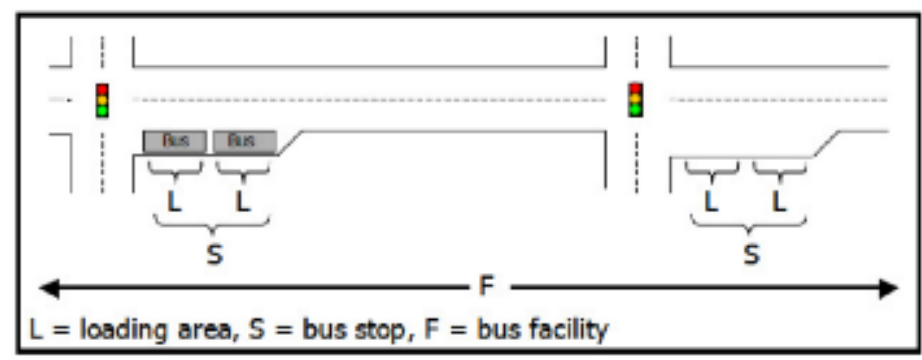

Gambar 2. konsep awal bus-stop

Sumber: Highway Capasity Manual (TRB,2000)

Terminal bus yang ada di (gambar 2) dapat didefinisikan sebagai fasilitas untuk berteduh dan penampung penumpang dari beberapa bus jalur untuk interkoneksi atau transfer ke jenis transportasi, misalnya: sepeda, MRT, LRT, dll. Kapasitas terminal bus dapat didefinisikan sebagai jumlah bus yang dapat dilayani oleh terminal berdasarkan frekuensi perwaktu untuk setiap jalur bus, karena setiap terminal memiliki desain yang berbeda-beda serta memiliki faktor-faktor umum berikut yang dapat mempengaruhi kapasitas terminal dan perlu dipertimbangkan:

- Perencaan operasi lalu lintas

- Penjadwalan kedatangan bus

- Terminal design

- Tujuan dan fungsi dari halte bus

- Jenis jalur bus

- Kemacetan lalu lintas dan lalu lintas lainnya.

\section{Design}

Secara etimologis istilah desain berasal dari Bahasa inggris yaitu reka rupa, rencana dan rancangan. Didalam proses design terletak beberapa aspek yaitu: estetika, fungsi dan aspek2 lainnya yang sesuai dengan pemikiran kemanusiaan. Berdasarkan pembagiannya terdapat beberapa tipe atau jenis desain:

- Desain grafis adalah proses komunikasi menggunakan elemen visual, seperti tulisan, bentuk, dan gambar yang dimaksudkan untuk menciptakan persepsi akan suatu pesan yang disampaikan.

- Desain produk adalah proses menciptakan produk baru yang akan dijual oleh perusahaan untuk pelanggannya. Sebuah konsep yang sangat luas, pada dasarnya generasi dan pengembangan ide-ide yang efektif dan efisien melalui proses yang mengarah ke produkproduk baru.

- Desain busana adalah seni yang merancang dan membuat pakaian dan aksesoris, termasuk perhiasan, topi, sepatu, dasi dan ikat pinggang. Mode adalah bidang yang sangat kompetitif, dengan desainer baru mencoba untuk memasuki pasar setiap hari.

- Desain interior adalah perancangan tata letak dalam ruangan baik rumah, perkantoran, mall, hotel, layout display gerai, bahkan tata panggung pertunjukan. Perancangan dan penataan tata letak dalam ruangan ini bertujuan untuk memaksimalkan penggunaan dan fungsi ruangan dan memberikan rasa nyaman dengan memaksimalkan space ruangan yang ada dan memperindah estetika ruangan.

\section{Perkembangan Desain dalam bidang mode dan art-product di Indonesia}

Perkembangannya di Indonesia dipengaruhi budaya Eropa dan Asia Tenggara terutama Jepang dan Korea Selatan yang mendorong trend fashion, sedangkan Amerika, Eropa dan Jepang mendorong desain arsitektur dan interior. Trend dalam hal desain cenderung meniru gaya barat terutama dibagian pemakaian bahan. 


\section{Tipologi}

Dalam perancangan bangunan stasiun transit bus, perlu dilakukan studi terlebih dahulu agar dapat lebih mengetahui program utama dan program yang dapat disesuaikan dengan konteks lingkungan sekitar sehingga diperlukan pembedahan bangunan-bangunan stasiun transit yang sudah ada dengan memperhatikan perkembangannya. Berikut beberapa teori dan penjelasan singkatnya, yang akan membantu selama proses perancangan

\section{Tipe}

Kata tipe berasal dari bahasa latin "typus" yang berarti suatu sosok, atau suatu pola. Lalu dalam perkembangan akhir kata ini dipakai dalam beberapa keadaan yang menunjukan, antara lain sifat umum suatu bentuk, kategori, jenis, aturan, contoh, dan model (Tjahjono, 2000). Untuk pemahaman lebih lanjut, secara simpel Rafael Moneo mendefiniskannya sebagai konsep yang mendeskripsikan suatu grup objek dengan karakter struktur formal yang sama (Moneo, 1978).

Dalam konteks perencanaan dan pengembangan kota membaca keadaan kota merupakan hal fundamental dan logika tipe (typology) bentuk bangun berperan besar didalamnya. Christopher C.M. Lee dalam disertasinya "The Fourth Typology" menyatakan Tipologi berperan seutuhnya (maksimal) sebagai alat heuristis/ penyelidikan. Dengan konteks kota sebagai lingkup pembahasan Lee dalam disertasinya, menunjukan penyelidikan yang dimaksud merupakan penyelidikan keadaan (aspek-aspek) kota. Untuk dapat menganalisis lebih banyak konteks penyelidikan suatu pembahasan harus terlebih dahulu memahami beberapa tipe yang ada dalam teori Christopher C.M.Lee sebagai berikut:

\section{Proto-tipe}

Kata "Proto-tipe" diadopsi oleh bahasa inggris dari bahasa Yunani kuno "prototypon" pada tahun 1590. Prototypon sendiri berasal dari kata protos (pertama) dan typos (cetakan) yang berarti pertama atau bentuk primitif. Proto-type menunjukan tipe bangun baru yang muncul dan dilatar belakangi suatu perubahan keadaan di suatu tempat. Perubahan tersebut dapat termasuk di dalam aspek lingkungan hidup, sosial-ekonomi, dan aspek-aspek lain. Proto-tipe berfungsi sebagai alat untuk membaca pola yang sedang dalam terjadi dalam konteks lingkungan setempat sehingga proto-tipe ini dapat membantu mempelajari perkembangan kawasan atau kota.

\section{Stereo-tipe}

Stereo-type lebih mempelajari pada tipe bangunan yang paling banyak dipakai sesuai dengan fungsi bangunannya. Misalnya kegiatan sehari-hari pelajar yaitu belajar, mengerjakan tugas dan sebagainya tetapi kegiatan ini akan berbeda secara tipe belajar antara orang di sekolah A dengan di sekolah B tetapi memiliki kriteria yang sama.

\section{Arche-tipe}

Arche-tipe mengacu pada bentuk ideal berdasarkan suatu variabel. Pada arche-tipe ini lebih mementingkan kebutuhan ideal berdasarkan fungsinya misalnya pada kantor sewa, fungsi utamanya adalah bekerja dan membayar iuran sewa dengan seminimnya sehingga yang cocok adalah menerapkan konsep tipe open-plan yang memanfaatkan ruang dengan semaksimal mungkin tanpa menbuang cost yang berlebihan untuk membuat sekat-sekat ataupun membuang space untuk membentuk beberapa ruang.

Archetype Dalam proyek ini berperan dalam pembedahan studi preseden untuk mendapatkan rancangan yang ideal dalam suatu aspek, dengan mengekstraknya dari perbandingan dengan proyek-proyek lain. Arche-type dalam pembedahan ini dilakukan untuk mencari rancangan ideal untuk setiap kategori ruang yang dibutuhkan, kemudian akan "dirajut" menjadi satu bangunan kompleks dan mengacu pada perilaku kebutuhan milenial 


\section{Genre}

Seiring perkembangan zaman, perkembangan jenis kegiatan atau program untuk mewadahi suatu bangunan semakin beragam dan tidak terbatas tetapi fungsi utama bangunan selalu tetap sama. Sebagai contoh, fungsi bangun pusat pemberlanjaan sering disebut dengan penamaan berbeda, seperti shopping mall, plaza, pusat pasar dan sebagainya. Perubahanperubahan yang terjadipun tidak menunjukan perbedaan pola kegiatan yang signifikan dan tetap memiliki prinsip dan pola perancangan yang sama. Dengan mengetahui fungsi bangun proyek berdasarkan pola kegiatannya yaitu fungsi bangunan stasiun bus, riset-riset yang harus dijalankan akan lebih mengacu pada pola perkembangan tipologi bangunan stasiun dari masa ke masa.

\section{Hubungan Antara Arsitektur-Tipe-Perilaku Serta Nilai Kesejamanan}

Stasiun Transit Bus secara umum merupakan fasilitas operasi atau tempat pemberhentian angkutan umum bermuatan massa secara teratur untuk menaik turunkan penumpang. Umumnya paling tidak memiliki satu jalur dan bangunan utama yang menyediakan layanan tambahan seperti penjualan tiket dan ruang tunggu. Seiring perkembangannya kota dan status masyarakat, fungsi stasiun dapat memiliki fungsi-fungsi lain yang melebihi dari fungsi utama stasiun.

Hubungan antara perkembangan stasiun transit bus dengan millennials yang sekarang mendominasi sebagai economic creative harus dipadukan dalam satu arsitektur yang dapat menjadikan perubahan dalam fungsi awal stasiun yaitu hanya tempat transit menjadi tempat untuk berekspresi, berkumpul, dan bekerja tetapi tetap harus memiliki esensi dari stasiun transit tersebut.

\section{ANALISIS}

Stasiun Transit ini harus mengikuti arus perkembangan zaman yang sekarang lebih modern yang harus disesuaikan dengan perilaku milenial agar pemakai kendaraan umum bukan hanya generasi $X$ tetapi dapat didominasi oleh Generasi Milenial yang berada didaerah komuter, salah satu untuk mendorong pemakaian kendaraan umum adalah dari tempat tunggunya terlebih dahulu (stasiun). Jika stasiunnya didesain mengikuti perkembangan jaman dan memiliki konsep bangunan maupun ruang, hal ini memungkinkan untuk menarik perhatian dari generasi milenial hingga generasi setelah milenial. Dengan mengacu pada metode seperti berikut:

\section{Tapak Proyek}

Metode analisis data dilakukan terhadap milenial yang berada di kawasan Jakarta yang masyarakat milenialnya juga merupakan bagian dari penduduk komuter, merupakan tahap penentuan lokasi tapak. Setelah itu dilakukan analisa makro untuk melihat penduduk komuter terbanyak yang datang ke Jakarta. Blok-M merupakan tempat pemberhentian terbanyak, lalu dari Blok-M menyebar ke sekitar Jakarta Selatan. 


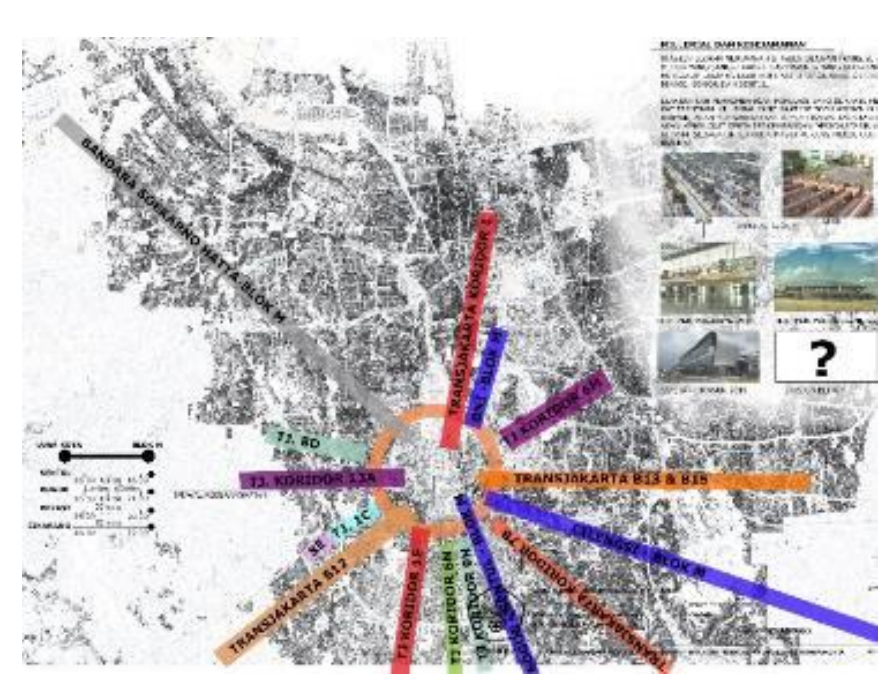

Gambar 3. Analisis makro di Blok-M, Jakarta Selatan

Sumber: Penulis, 2019

Dengan melakukan analisis yang berada di Blok-M terlihat penduduk komuter yang datang ke Jakarta menggunakan kendaraan umum (bus) dari Bogor, Depok, Tangerang, Bandung, serta Bekasi yang dikarenakan letak posisi yang strategis terhadap kawasan industri kreatif di Jakarta dan berbatasan dengan industri Bodetabek. Dalam hal ini, jumlah bus yang mendatangi stasiun Blok-M sangat banyak, bus luar kota yang datang ke stasiun Blok-M tidak memiliki area pemberhentian atau parkir serta ruang tunggu penumpang-penumpangnya sedangkan konsep luar kota/antar kota diperlukan waktu jeda/tunggu dari satu destinasi ke destinasi lainnya. Setelah mengetahui mengenai analisa makro, meso lalu dilakukan analisa mikro yang berdasarkan analisa lingkungan sekitar serta tidak luput juga dengan analisa user yang dikarenakan bangunan ini akan terdapat bentrokan antar kebutuhan pengguna.

User yang akan memakai fasilitas ini berupa pendatang, transit, kepergian serta menjadikan sebagai titik temu. Lalu pengguna ini kebanyakan memiliki 2 sifat yang dominan yaitu pengguna yang hanya akan menggunakan fasilitas sesuai fungsinya berupa transport (generasi $\mathrm{X}$ ) serta tidak luput dengan adanya tempat relaksasi yang biasanya dilakukan dengan mengunjungi retail. Satu sifat lainnya merupakan pengguna yang lebih fleksibel dalam aktifitasnya yang dapat melakukannya dimana saja yaitu milenial. Milenial memiliki sifat yang lebih ingin bersosialisasi/bertukar pendapat, serta lebih menyukai tempat-tempat yang instagramable. (lihat Gambar 4).

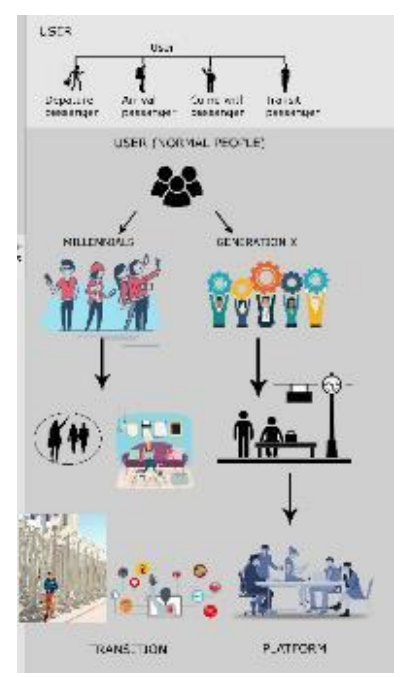

Gambar 4. Diagram user

Sumber: Penulis, 2019 


\section{Tipologi}

Tipologi bangunan merupakan sebuah studi/ pengkajian tentang penggabungan elemenelemen yang memungkinkan untuk digabungkan serta mengklasifikasi organisme arsitektur melalui tipe-tipe. Klasifikasi mengindikasikan suatu perbuatan meringkas yaitu penamaan yang berbeda, yang masing-masing dapat didefinisikan dan menyusun dalam kelas-kelas untuk melakukan identifikasi data dan memungkinkan membuat perbandingan-perbandingan pada kasus-kasus yang serupa (Anthony Vidler,2014).

Metode tipologi merupakan salah satu metode yang dapat digunakan untuk memahami, mengidentifiasi serta menganalisa dalam bidang arsitektural. Menurut Rafael Moneo, analisa tipologi dibagi menjadi 3 fase:

- Menganalisa tipologi dengan cara melihat dari sejarah untuk mengetahui ide awal dari suatu komposisi, atau mengetahui asal usul kejadian pada suatu objek arsitektural.

- Menganalisa tipologi dengan cara mengetahui fungsi suatu objek.

- Menganalisa tipologi dengan cara mencari bentuk sederhana suatu bangunan melalui pencarian bangunan dasar serta sifat dasarnya.

\section{Tipologi Stasiun Bus}

Komposisi perkembangan stasiun bus dari yang hanya berupa shelter di pinggir jalan, lalu adanya fasilitas tambahan didekat shelter misalnya tempat perdagangan, setelah mulainya perkembangan waktu dilakukan penambahan fasilitas berupa parking untuk penumpang yang park and ride (untuk perjalanan jauh menggunakan bus), hingga menjadi bangunan yang disebut bangunan stasiun bus yang dikarenakan perilaku yang semakin berubah-ubah.

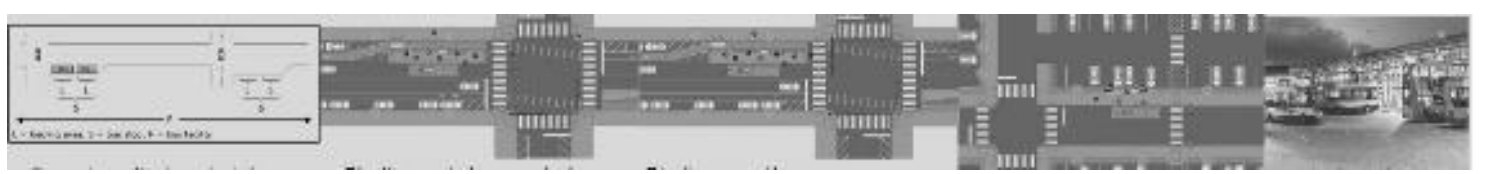

Gambar 5. Perkembangan Program halte-stasiun bus Sumber: Highway Capacity Manual (TRB,2000)

Perkembangan bangunan serta fungsi stasiun bus yang ada di Indonesia, dari sebatas halte kemudia menjadi tempat atau bangunan tunggu serta menjadi bangunan trans-programming.

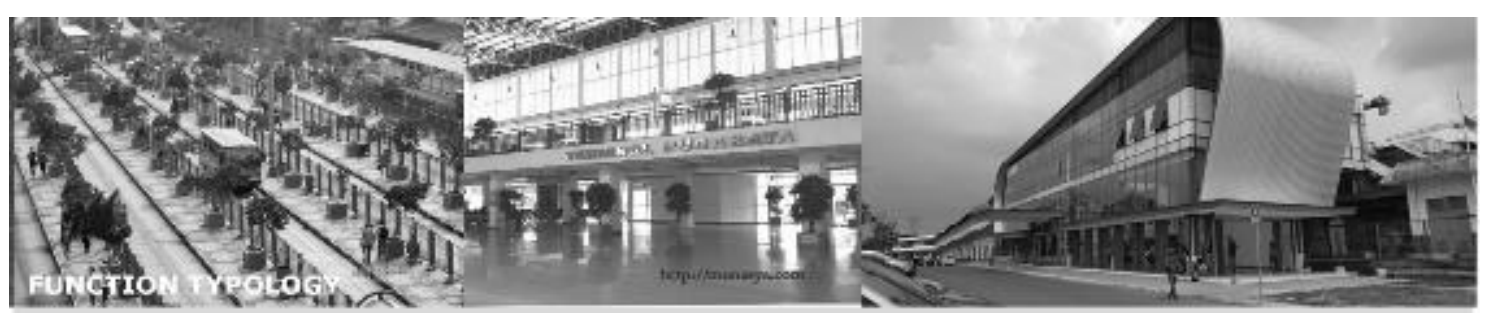

Gambar 6. Perkembangan bentuk bangunan stasiun bus di Indonesia Sumber: google.com

\section{DISKUSI DAN HASIL}

Setelah melakukan analisis, dilakukan pembaruan baru terhadap stasiun bus Blok-M dengan menambahkan program-program baru serta pergantian bentuk bangunan dari yang lalu menjadi lebih ke arah trend milenial. Desain total luasan bangunan baru mencapai \pm $25.000 \mathrm{~m}^{2}$ memiliki program utama yaitu sebagai tempat perpindahan bus di lantai dasar $(40 \%)$, retail $(30 \%)$ di lantai 2 , creative space $(20 \%)$ di lantai 3 serta exhibition roof $(10 \%)$ di rooftop sedangkan yang existing hanya mencapai $\pm 7.000 \mathrm{~m}^{2}$ yang berupa shelter panjang sebagai area menunggu bus. 


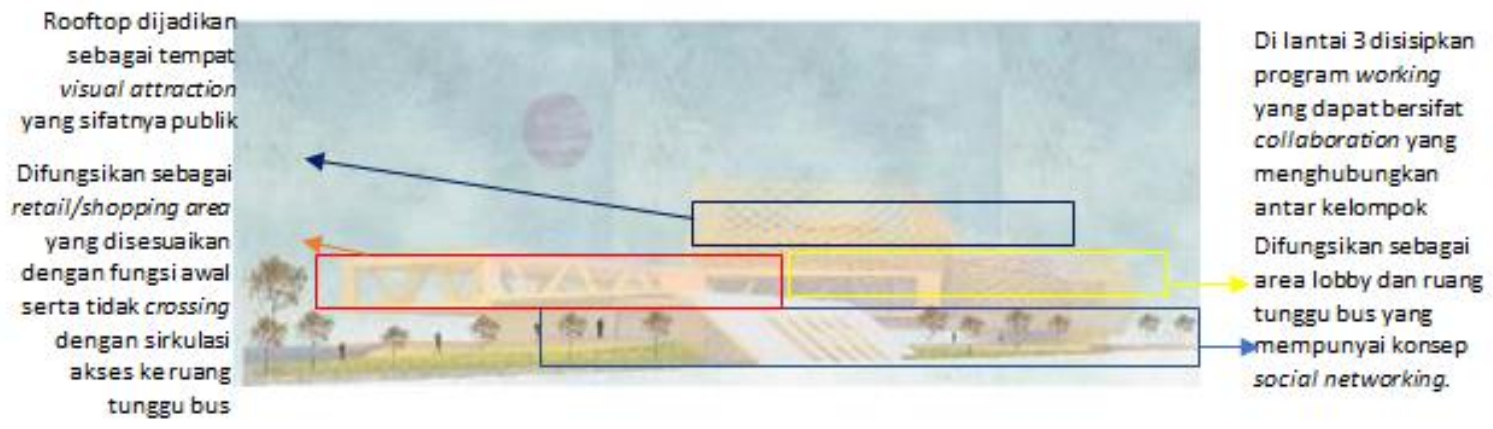

Gambar 6. Perspektif Exterior

Sumber: Penulis, 2019

Dengan melakukan pendekatan tipologi dan analisis berdasarkan pola kawasan dan perilaku milenial yang sudah dijelasin di bab 3 dan 4, ide pola penyusunan berdasarkan

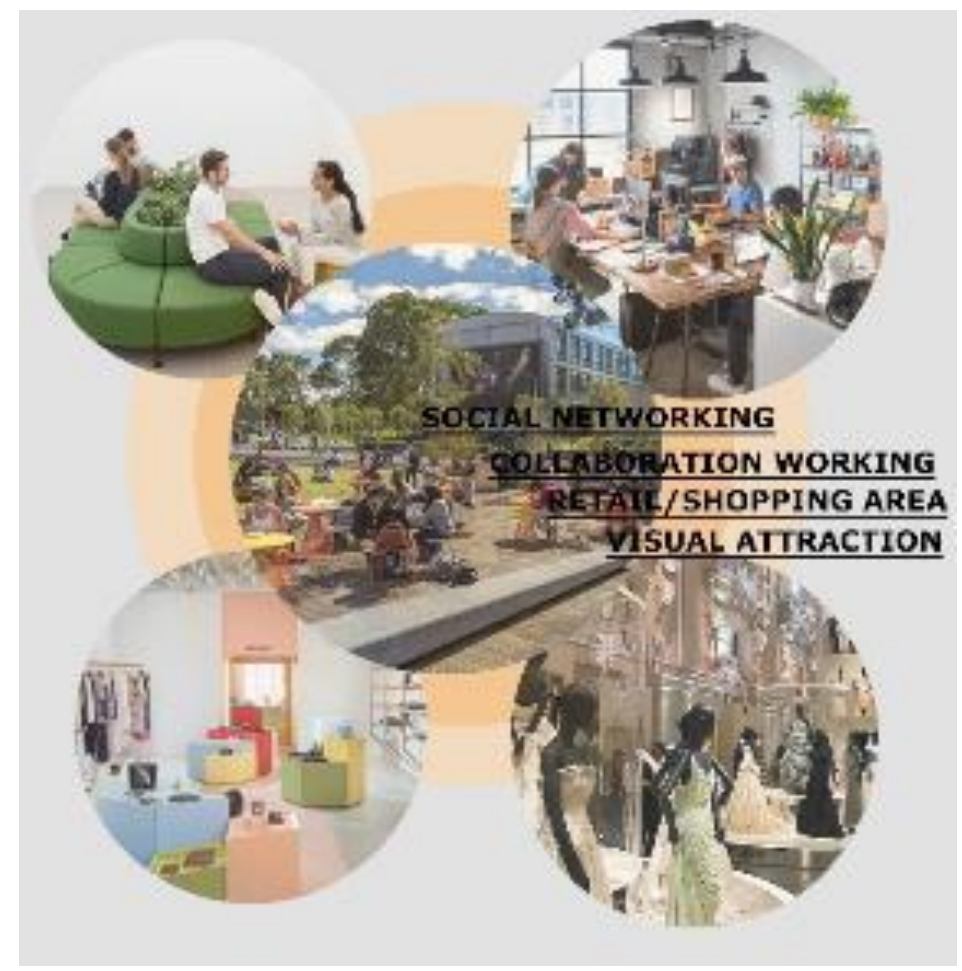

Gambar 7. Ide Dasar Pemograman Sumber: Penulis, 2019

Social networking, social collaboration working and visual attraction. Social networking lagi diminati oleh milenial karena dapat berbagi ilmu dan menambah komunitas, lalu kolaborasi project yang juga sekarang diminati karena sifat milenial yang kreatif sehingga dilakukan kolaboratif yang berhubungan dengan ekonomi kreatif serta pameran-pameran atau show yang dilakukan untuk mengelar launching atas hasil karyanya. Bangunan ini dapat memberikan pelayanan terutama dalam hal industri kreatif berbentuk exhibition, creative-space serta sharing area yang sesuai dengan bentuk perilaku milenial. 


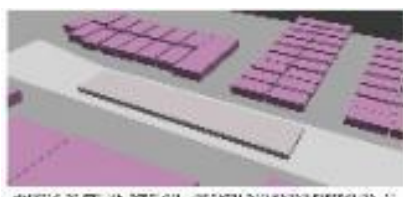

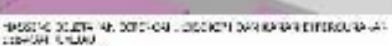
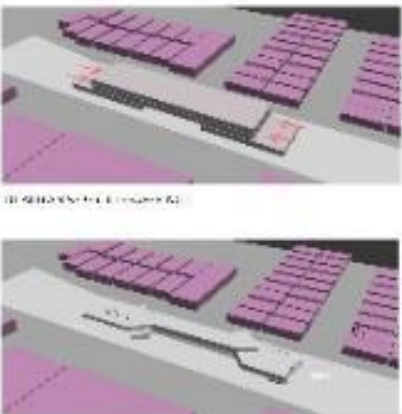

a.sive

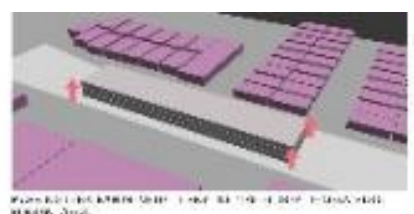

:avesing
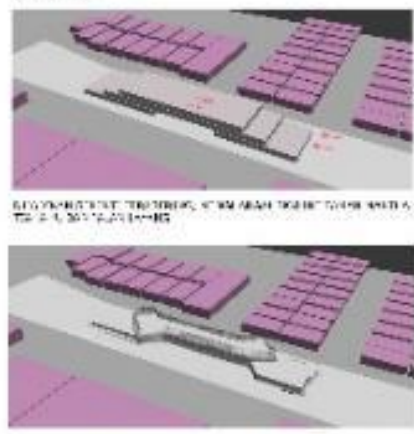

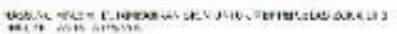
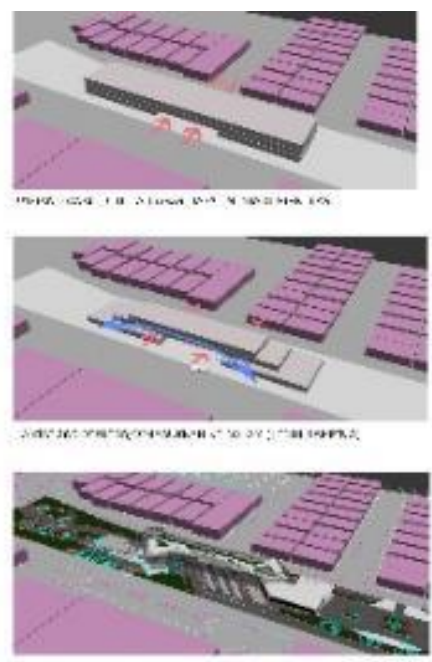

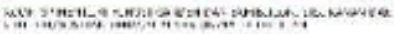

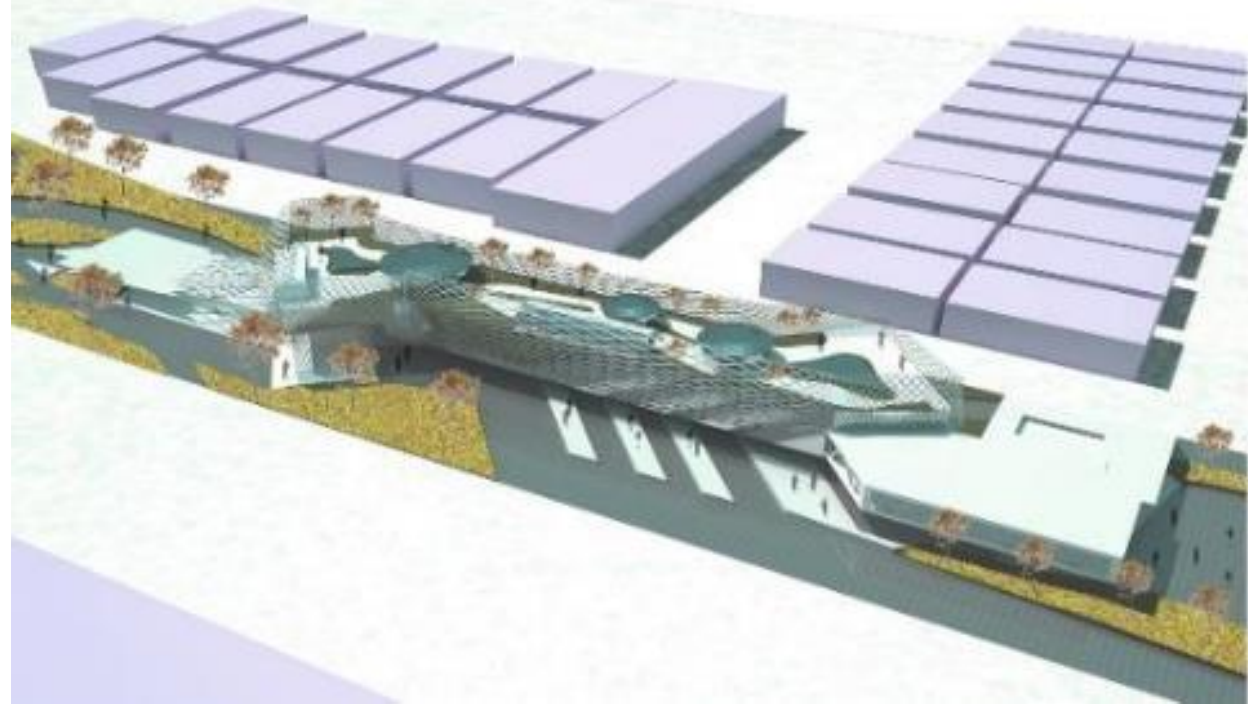

Gambar 8 dan 9. Design Scheme dan Bird Eye View Sumber: Penulis, 2019

Proses desain dilakukan dengan tahap mengikuti bentukan tapak lalu dilakukan proses rotasi dan cut di beberapa bagian sehingga mendapatkan hasil seperti bangunan mengikuti pergerakan sirkulasi kendaraan serta skyline sekitar. Sebelum hasil akhir seperti exterior yang diatas, terdapat pemikiran awal seperti bentukan, susunan dan pola sirkulasi mengikuti tipologi dari stasiun serta memasukan bentukan dan fasad berdasarkan karakter setempat.

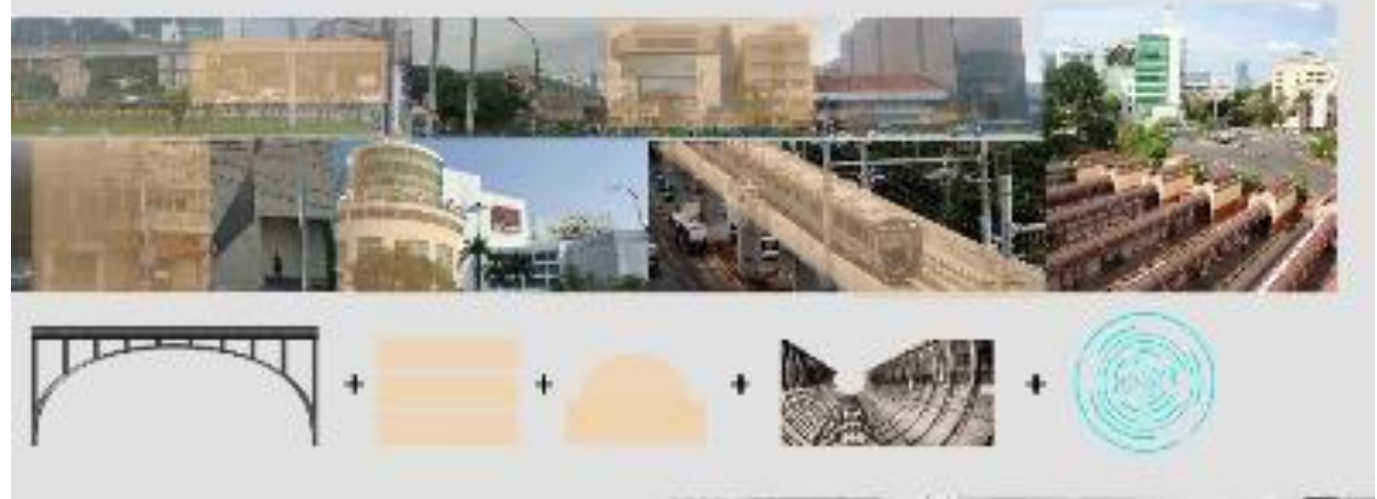

Gambar 10. Karakter Setempat

Sumber: Penulis, 2019 
Berikut merupakan beberapa suasana ruang yang ingin diharapkan:

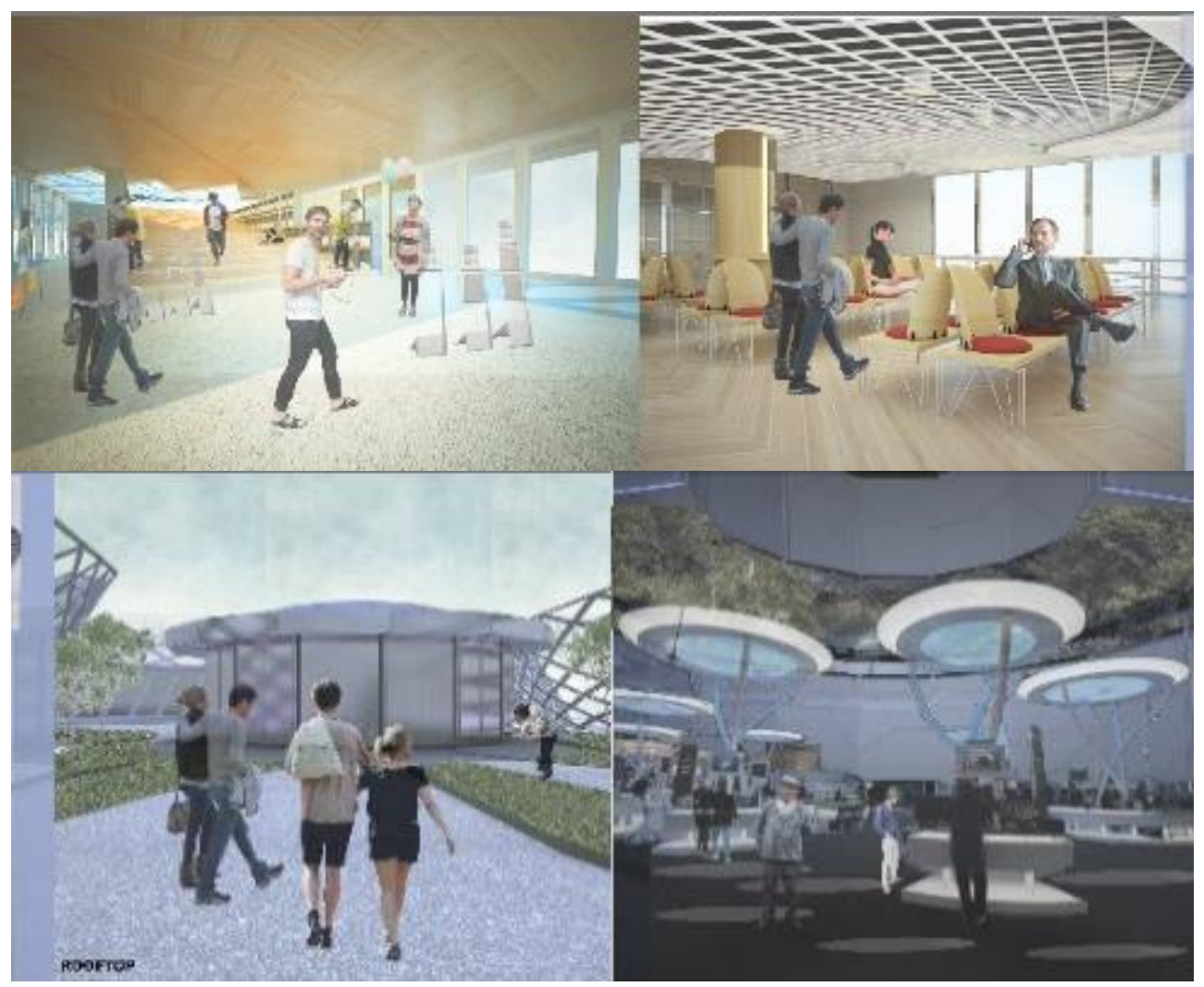

Gambar 11. Ruang Interior

Sumber: Penulis, 2019

\section{KESIMPULAN DAN SARAN}

Pembaharuan Stasiun Blok-M memiliki peranan untuk membantu pergerakan komuter dan menyediakan tempat untuk para milenial berkumpul untuk melakukan sharing dan kolaborasi dalam bidang kreatifitas serta disediakan tempat untuk melakukan kreatifitasnya yang dapat meningkatkan ekonomi kreatif di Indonesia. Fungsi bangunan awal lantai 1 dapat dijadikan sebagai area komersil, dapat menerapkan konsep setempat/kontemporer dari fungsi bangunan sekitar.

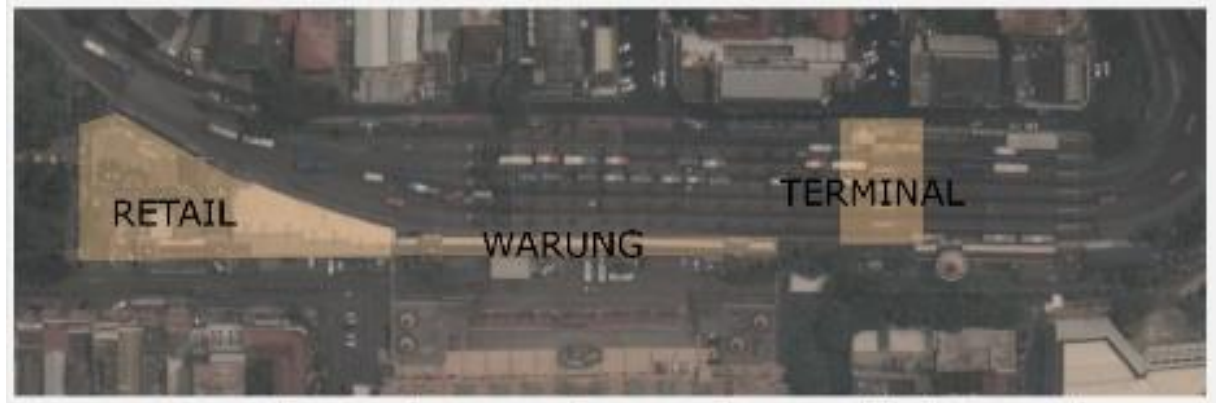

Gambar 12. Penzoningan Fungsi Site Awal

Sumber: Penulis, 2019

Fungsi awal dari stasiun bus di blok $m$ yang hanya memiliki fungsi retail, warung dan terminalnya serta bus yang berada disite memiliki 2 tipe yaitu bus dalam kota dan luar kota, tetapi kondisi existingnya tidak memiliki tempat pemberhentian untuk bus luar kota. 


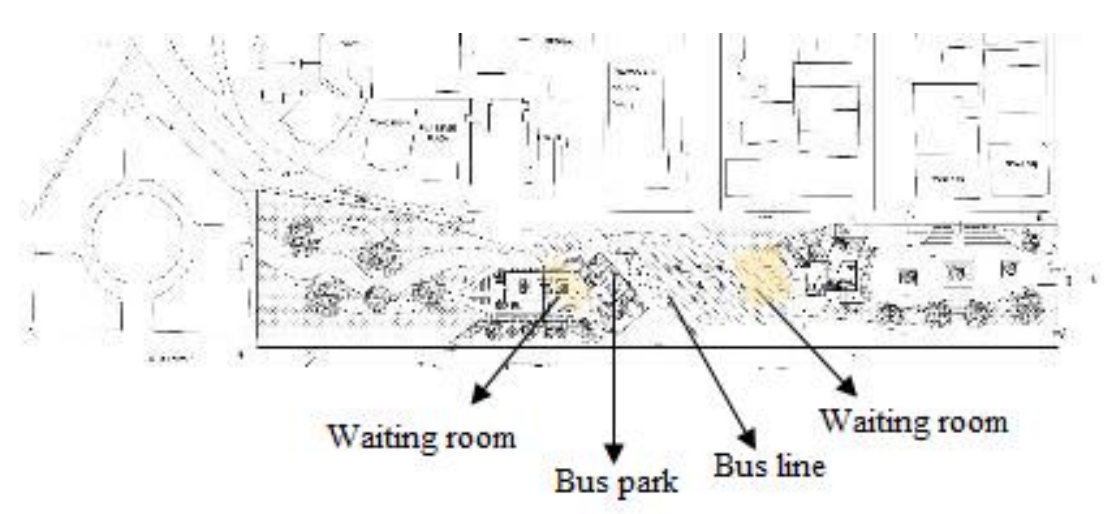

Gambar 13. Pembaruan Fungsi Baru pada Stasiun Bus Sumber: Penulis, 2019

Akses pencapaian ke bangunan dapat didesain mengikuti keadaan sekitar yang dekat dengan taman, hendaknya desain ini menambah konteks alam dibagian luar bangunan maupun didalam bangunan. Berdasarkan hasil diskusi yang telah dibahas sebelumnya, diharapkan untuk peneliti selanjutnya untuk dapat melakukan penelitian atau pembahasan dengan melakukan metode perancangan lainya yang berdasar pada kaum milenial terutama di perilakunya agar adanya kecocokan antar perilaku, fungsi dan desain bangunan.

\section{REFERENSI}

AASHTO. (2010). Geometric Design Guide for Transit Facilities on Highways and Streets, Chapter5 Off-Line Transit Facilities. Washington: American subcommittee on design

AASHTO. SKF \& SRA. (1999). Better Bus Stops (in Swedish: Bättre busshållplatser). Svenska kommunförbundet (SKF); Swedish Road Adminstration (Vägverket); Svenska Lokaltrafikföreningen.

Basewanox, J. (2017). Retrieved from World Trade Center Transportation Hub: https://issuu.com/janbaxewanos/docs/case_study_the_wtc_transportation_h

Beaton, C. (2015). Retrieved from Why Millennials Are so Stressed-and What to Do about It: https://www.psychologytoday.com/us/blog/the-gen-y-guide/201509/why-millennials-areso-stressed-and-what-do-about-it

Billy, A. T. (2017). Retrieved from MRT Jakarta Mampu Mengangkut 173 Ribu Penumpang Per Hari: http://www.tribunnews.com/bisnis/2017/10/31/mrt-jakarta-mampu-mengangkut173-ribu-penumpang-per-hari

Coconuts Jakarta. (2017). Retrieved from Jakarta Ranked One Stressfull Cities World Global Study: https://coconuts.co/jakarta/news/jakarta-ranked-one-stressful-cities-world-globalstudy/

Cosmopolitan. (2016). Retrieved from Generasi Millennial Malas Bekerja: http://www.cosmopolitan.co.id/article/read/12/2016/11108/generasi-millennial-malasbekerja-baca-dulu-alasannya

Dian, M.. (2015). Retrieved from Hewan Peliharaan yang Berdampak Menyehatkan:https://lifestyle.kompas.com/read/2015/07/20/160000023/5. Hewan.Pelihar aan.yang.Berdampak.Menyehatkan

Karima, A. (2014). Faktor-faktor yang Mempengaruhi Stress Kerja. Retrieved from https://www.academia.edu/8666241/Faktor-faktor_yang_Mempengaruhi_Stress_Kerja

republikbjm. (2015). Retrieved from Survei membuktikan, banyak pekerja di kota-kota besar stress memuncak: https://republikbjm.wordpress.com/2015/04/20/survei-membuktikanbanyak-pekerja-di-kota-kota-besar-stress-memuncak/

SRA \& SKF. (2004). Road Design (VGU Sidoanläggningar). Swedish Road Adminstration SRA (Vägverket) and Svenska kommunförbundet SKF. 
SKL. (2013). Accessibility Measures for Public Transport (in Swedish: Framkomlighetsåtgärder för kollektivtrafiken) Stockholm: SKL.

SL. (1987 \& 1988). Dockningsterminaler, Utformning och utvärdering. Sockholm: Storstockholms Lokaltrafik (SL); Fastigheter AB med konsulthjälp från VBB VIAK.

Spenner, P. (2016). Retrieved from Inside the Millennial Mind: The Do's \&amp; Don'ts of Marketing to this Powerful Generation: https://www.forbes.com/sites/patrickspenner/2014/04/16/inside-the-millennial-mind-thedos-donts-of-marketing-to-this-powerful-generation-3/\#3ada0c6d2c87

TRB. (2000). Highway Capacity Manual HCM2000. TRB.

Wahyudi, M. (2016). Retrieved from Studi: Di Jepang, 37 persen generasi muda ingin kerja sampai mati: https://www.merdeka.com/uang/studi-di-jepang-37-persen-generasi-mudaingin-kerja-sampai-mati.html

Wendle, B. (1997). What Delays the Bus? (in Swedish Vad fördröjer bussen?). Lund: Lunds tekniska högskola: Institutionen för trafikteknik

Wijayanti, S. (2018). Retrieved from 10 Ciri Dasar Generasi Millennial: https://www.idntimes.com/life/inspiration/sinta-wijayanti-d/10-ciri-dasar-generasimillennial-c1c2/full 